\title{
The identification study for influence factors of execution efficiency of SMEs supportive policy
}

\author{
Xiangxue $\mathrm{Lu}^{*}$ \\ International Business School \\ Yunnan University of Finance and Economics \\ Kunming, China \\ 1810842206@qq.com
}

\author{
Dongping $\mathrm{Yu}$ \\ International Business School \\ Yunnan University of Finance and Economics \\ Kunming, China \\ 247096657@qq.com
}

\begin{abstract}
Under the background of "One Belt and One Road" and "the setting up of the investment bank", the new emerging business and trade in the southeast and south Asia area begin to explore its management and cooperation mode. This will largely promote the development of small and medium-size enterprises (SMEs) in these areas. On the basis of reviewing the existing researches, the author summarizes the main factors of the execution efficiency of SMEs supportive policy. Based on the hierarchical strategy, the author points out the promotion countermeasures for execution efficiency of SMEs supportive policy from the aspect of macro, medium and micro perspective for the government, financial credit institutions, and SMEs itself, which all contribute to SMEs' development smoothly and rapidly.
\end{abstract}

Key words - SMEs; supportive policy; execution efficiency; factor identification

\section{INTRODUCTION}

The ability of execution means we achieve the goals with good quality by making full use of resources. Generally, the effective execution of public policy is the inner power and strength reflected in the process that government fully schedule, control and use of resource so as to realize the policy goal [1]. However, this view tends to confine policy implementer to government agencies and their staffs. And this study regards the execution of public policy as the process of the policy executors, policy audience, and other relative social organizations effectively achieve the policy objectives by fully scheduling, controlling and using of resource.

Due to the important role of SMEs on the development of national economy, the government increasingly launches various supportive policies for SMEs. However, because of the complexity of interest structure and many other factors, some local governments cause deviation in varying degrees in the process of policy implementation [2]. What's more, scholars' previous researches on SMEs supportive policies are mainly focused on how to ease the SMEs financing difficulties and are mainly studies from the fiscal and taxation support policy [3-4] and financial support policies prospect [5-6]. These studies generally focus on macro policy-making, which lack the consideration and evaluation of the follow-up policy execution efficiency.

Through identification for the key factors of execution efficiency of SMEs supportive policy, the author puts forward

\footnotetext{
*Corresponding author
}

corresponding strategies which contribute to promote the execution efficiency of SMEs supportive policy according to the SMEs actual demands and different implementer.

\section{The FACTORS System OF SMEs Supportive PoliCy EXECUTION EFFICIENCY}

In the implementation process of financial support policy of SMEs, the central government departments, local finance department officials and SMEs are the Dynamic Game tripartite body [7]. Currently, in the support process for SMEs, there still are some unfavorable phenomenon, for example, single policy tool, inadequate policy supply, lack of policy implementation efforts. Therefore, the new model of support should be a "tripartite driven" mechanism in which the government-led, market intervened and social participated [3].

Based on the basis of the analysis for the existing literature, the writer summed up the government, SMEs and other social organizations are three important factors for policy execution efficiency. In addition to, the writer designed the third-level indicators system to identify the key factors and propose targeted recommendations.

\section{A. Government}

As the makers and implementer of supportive policies of SMEs, government play an important role in the process of promoting the development of SMEs. The academic world have a basic qualitative awareness of relationship between the government and implementation efficiency of supportive policies of SMEs.

The main implementer of policy (R1): The traditional policy main implementer often limited to government agencies and their staffs, which could easily result in single policy implementer and lack of supervision. Therefore, it is difficult to mobilize the enthusiasm of all participants in policy implementation. The main implementer of policy often decides formulation, execution and the following adjustment of policies. As social being, policy implementer' accumulation of knowledge, differences of ability to understand, whether will be driven by interest and the limit of values might have an important influence on the result of the policy implementation [8].

Since the central government are the policy makers and they tend to pay more attention to overall interests while the 
local governments are the implementer and they focus on the personal and regional interest, which result in a difference of interests between the makers and the implementer of policies. The level of identity of policy implementer, whether the execution attitude is firm, whether the execution is strong, and whether executor easily be driven by the interests selectively implement policies, all which have a crucial impact on the results of policy implementation.

In the process of implementation of SMEs supportive policy, the diversified participant can mobilize the enthusiasm of all participants, increase communication and interaction between subject and object, reduce the resistance and costs and improve implementation efficiency.

The policy execution system (R2): In the process of policy implementation, the efficient operation of the policy implementation system can integrate execution resource, standardize execution behavior, and ensure implementation results [9].

without constraints, power will breed corruption, the interests structure involved in the the implementation of the SME supportive policies is so complicated that continue efforts of strengthening internal supervision and control are necessary [10]. Real-time evaluation for policy implementation status and correction for the deviation behavior appears in the process of implementation of the policy can ensure the scientific and effective implementation performance.

Moreover, In order to ensure the implementation efficiency, We can apply accountability system to the implementation of SMEs supportive policies, and increase penalties for the behavior of deviating from the target, such as the behavior of additional, selective and distorting execution.

The policy execution resource (R3): Policy execution resource mainly include the required manpower and material resource, funds, information, authority resource, and scientific and feasible policy implementation plan, and effective and suitable method for execution. Policy execution resource is the basic security conditions of policy implementation.

The level of quality of human resources is closely related to the level of execution of government [11]. It is the knowledge reserve, professional level and skill level of policy implementer that determines whether they can accurately understand and effectively implement public policies. Sufficient high-quality human resources is an important guarantee for effective implementation of SMEs supportive policy.

The shortage of material resources will inevitably lead to adverse consequences of inefficient execution. Therefore, adequate supply of resources is an important prerequisite and guarantee for the effective implementation of public policies [12].

Adequate financial investment is the guarantee of implementation of public policy. Without required financial resources for support, it will be an empty promise for supporting SMEs [13].

Information is an important resources and prerequisite for the implementation of public policy. Distorted information will lead to the implementer' error judgment, which in turn affect the proper adjustment of public policy and achievement of the desired goal.

Policy execution environment (R4): Any execution of policy is restricted and influenced by the policy environment. Appropriate policy environment is good for the policy's effective implementation.

In order to promote the development of SMEs, we not only need the support and encouragement of fiscal policies and special funds from central government but also local governments should formulate and implement the relevant complementary policies, such as financing policy, land policy, tax policy, industry access policy [14]. Under the background of central government are continually vigorously support the development of SMEs, in order to SMEs have a fair competitive position and good market order, local governments should combine with its own region characteristics, local conditions and constantly reforms to create a good policy environment.

The development level of local economics has a great influence on the development of SMEs [15]. It is the development level of local economics that determines whether the local government have the strength to provide the required infrastructure, taxation and public services for the development of SMEs. Development of local finance is vital to sustained development of local economic, moreover, SMEs are a major component of our local economy.Therefore, the local governments should improve the construction of local financial system, increase financing channels for SMEs and promote the implementation of SMEs supportive policy.

Law is the guarantee of governments at all levels efficiently perform the public policy [16]. Only if we improve relevant legal system and process of dealing with issues according to the law, can we promote fundamentally the construction of law society, and make our government walk on the scientific and legal road. The higher the degree of the rule of law, the higher the implementation efficiency of the SME supporting policies.

The efforts of propaganda for policy have a vital influence on the transparency of information of public policy implementation, the timeliness of the spread and the effectiveness of feedback [17]. Central and local governments at all levels should increase propaganda for SMEs supportive policy, encourage SMEs to pay closely attention to the formulation and implementation of supportive policies and increase SMEs' the degree of identity and support for policies.

\section{B. Other social organizations}

Other organizations, such as social security agencies, commercial banks and insurance companies can contact directly with SMEs and have a direct impact on the development of SMEs. We should promote actively the development of credit guarantee institutions and improve other market-based instruments, rather than make use of the government supportive measures, such as credit grading system are more effective for the financing of SMEs [18].

The support willingness of bank financing (R5): first of all, 
SMEs tend to apply for a smaller amount loan, but the approval process and operation steps are the same as large enterprises, which makes the average operating costs of banks increased [6]. What's more, SMEs always have bad record during the past loans process. These factors lowed the willingness of commercial bank to lend to SMEs.

The threshold of bank financing (R6): Generally, commercial Banks implement the mortgage guarantee system, and because of the SMEs' small size, weak competitiveness and the less fixed assets for mortgage shortage, commercial banks tend to have a higher risk when lending to SMEs. In turn the banks have to raise the loan interest rates to them.

The maturity level of credit guarantee system (R7): Credit guarantee agencies have the advantage of reducing the degree of information asymmetry and credit-enlarging, lowering transaction costs between bank and SMEs and so on. Therefore, improving credit guarantee system can effectively alleviate the financing difficulties of SMEs.

The supportive willingness of private financing (R8): Due to the high threshold of formal financial institutions can not meet financial needs of SMEs, therefore, private financing model develop rapidly. Compared with the bank deposit interest rates, private financing can bring more substantial benefits to the owners of idle capital, therefore, private financing model is popular with the owner of the idle capital [20].

The threshold of private financing (R9): Compared with the formal financial institutions, private capital has the advantages of less approval process, less intermediate link and high efficiency. However, because of their purpose for interest, the informal loan rate is higher than the bank during the same period.

The maturity level of private financing system (R10): Private financing system is beneficial for relieving the contradictions between capital supply and the demand, thus, it establishes a connection between those who have surplus capital and who lack, then the system regulate it, and improve the service efficiency of capital. At present, the development of private financing system is not perfect, not only the private financing mode accounts for a small proportion in available financing channel of SMEs, but also the relevant legal regulation of private financing model pays too much attention to crack down on illegal lending practices and neglects to support and protect the lawful private financing activities [20].

\section{SMES}

The degree of identity of SMEs (R11): In the implementation process of supportive policies of SMEs, SMEs are the target groups, whose attitude towards supportive policy has a profound influence on the implementation efficiency of SMEs supportive policies.

The degree of identity of employees in enterprise (R12): The effective execution of SMEs supportive policy need employees in enterprise have clear understanding and high degree of identity for the connotations of policy, the meaning of execution, their duty in the implementation of supportive policy. Only in this way, can we make sure the employees' behavior consistent with the enterprise's request.

The execution willingness of employees in enterprise (R13): understanding and identity of employees for the policies can reduce the resistance in policy implementation, moreover, the implement willingness of employees determines the outcome of policy implementation. Then, apart from the understanding and identity of employees for supportive policy, we also need make sure employees at all levels can have a positive altitude, mutually coordinate and cooperate with each other to improve the efficiency of the policy.

The enterprise culture (R14): Enterprise culture determines the behavior style of an enterprise. Open, competitive enterprise culture tends to make enterprises have a strong ability of obtaining information and using new things and new system to achieve their own development.

The enterprise credit (R15): Actually, the situation of financing difficulties of SMEs in our country result from not only the macro policy economic and the external financing environment, but also the SMEs' lacking of credit.

The entrepreneur ability (R16): Entrepreneur ability is entrepreneur's quality, character, knowledge, the style in the innovation activities and comprehensive ability, and the relationship coordination ability, enterprise management ability and entrepreneur's literacy reflected in this basis. As the leader, entrepreneurs play a significant role on the development of enterprises.

Due to information asymmetry in the past, SMEs unable to promptly get the details of support policies for their development, which in turn lead to SMEs can not timely found and seize the opportunities of development. Therefore, entrepreneurs' ability to obtain information is crucial to the implementation of SMEs supportive policy.

The ability to identify opportunities of entrepreneur has a decisive role on the company's future survival and development. Whether SMEs can actively and effectively seize the opportunity and take advantage of various government's supportive policies to achieve their own healthy and rapid development depends largely on the entrepreneur's ability to identify opportunities.

The execution ability of entrepreneurs is one of key factors in the performance of policy enforcement [20]. SMEs entrepreneur should actively corresponding to the government's call and take full advantage of supportive opportunity of government to achieve their development.

Based on the above analysis, We can build the following table 1 of key factors system.

\section{THE HIERARCHICAL STRATEGY}

SMEs have an significant influence on improvement for the development of national economy, increase of employment, promotion of science and technology innovation and social stability and so on. Therefore, it is of great significance to promote execution efficiency of the SMEs supportive policy.

Based on existing research, this paper summarized 13 main 
factors of the execution efficiency of SMEs supportive policy. And this paper adopted hierarchical strategy to improve execution efficiency of SMEs supportive policy.

\section{A. Macro level management countermeasures}

First of all, as the maker of SMEs support policy, it's the government's responsibility to formulate corresponding support policies according to the SMEs development

TABLE I. THE KEY FACTORS SYSTEM OF SUPPORTIVE POLICY EXECUTION EFFICIENCY OF SMES

\begin{tabular}{|c|c|c|}
\hline The first grade indicators & The second grade indicators & mark \\
\hline \multirow{4}{*}{ Government } & The main part of policy implementation & $\mathrm{R} 1$ \\
\hline & The policy execution system & $\mathrm{R} 2$ \\
\hline & The policy execution resources & $\mathrm{R} 3$ \\
\hline & The policy execution environment & $\mathrm{R} 4$ \\
\hline \multirow{6}{*}{ Other Social Organization } & The supportive intention of bank financing & R5 \\
\hline & The threshold of bank financing & R6 \\
\hline & The maturity level of credit guarantee system & R7 \\
\hline & The supportive intention of private financing & $\mathrm{R} 8$ \\
\hline & The threshold of private financing & R9 \\
\hline & The maturity level of private financing system & R10 \\
\hline \multirow{4}{*}{ SMEs } & The identity of enterprise & R11 \\
\hline & The entrepreneur ability & R12 \\
\hline & The enterprise culture & R13 \\
\hline & The enterprise credit & $\mathrm{R} 14$ \\
\hline
\end{tabular}

situations and the actual demand. Second, government should improve the execution efficiency of public policy. After formulated, the policy entered into implementation stage. Only strong execution can ensure the desired effect comes true. Therefore, government needs to choose the right implementer, offer required resource and strong supervision, and understand the status of implementation of SMEs the supportive policy, timely and rectify the deviation. Moreover, government can increase the implementation of the accountability system to guarantee the efficiency of policy implementation. In addition, governments need to strengthen the supervision of financial and credit institutions and encourage the development of the third party credit guarantee institutions that provide practical services for SMEs. Finally, it should strengthen the training of SMEs financial services talent and provide personnel training for the SMEs, and improve the level of business and the efficiency of service.

\section{B. Medium level Management countermeasures}

In order to promote SMEs smoothly and rapidly develop, financial institutions should actively response to the government's call and insist on increasingly innovating financial products and services according to the situation of development of SMEs. Financial institutions should perfect the related mortgage system and the authentication method of the pledge to provide convenient financing ways for SMEs.
C. Micro level management countermeasures

As the recipient of supportive policies, the SMEs also have a great influence on implementation of supportive policies. Therefore, in order to promote efficiency execution of SMEs supportive policy, the following actions should be taken. First of all, SMEs need continuously take every efforts to improve the acquisition channels of information, and understand governments' supportive policies and seize the opportunity to realize their own rapid developments. Second, SMEs should improve their own quality, keep good credit of the enterprise, set up long-term goals, and strengthen enterprise financing ability. Finally, SMEs should constantly introduce high-quality management elites to improve the enterprise's operation ability.

\section{ACKNOWLEDGEMENT}

In the process of the selection of topic and research, I got the kindly care, constantly encouragement and patient guidance from my tutor Yu Dongping. She has serious attitude and strives for perfection the work style, which deeply influence and inspire me. She gave me careful guidance not only in academic research, but also in the thought and daily life. Now, I would like to express my sincere thanks and high respect to her. 


\section{REFERENCES}

[1] J. Han, "Policy execution research review," Journal of Hebei industrial science and technology, Hebei Journal of Industrial Science and Technology, vol. 29, 2012, pp. 343-346.

[2] H. Ding and M.Y. Liang, "Designing Evaluation Indicators System for Measuring Local Government's Capacity in Executing Public Policy-From the Perspective of Legitimacy of Local Government," Journal of Jiangsu Administration Institute, 2014.

[3] C. Liu, "The shift of paradigm for the fiscal and taxation support policy of SMEs," Social Science in China, vol. 34, 2013, pp. 60-68.

[4] L.Q. Mo, "Structural tax cuts and new opportunities of development of SMEs," Shanghai Journal of Economics, vol. 33, 2014, pp. 103-110.

[5] F.J. Wu, "The research for implementation experience of support policy of science and technology and financial in jiangsu province," Science and Technology Management Research, vol. 35, 2015, pp. 77-81.

[6] M. Wang and W.W. Zhang, "Under the new normal middle enterprise financing characteristic and countermeasures," Economic Review, vol. 32, 2016, pp. 56-59.

[7] N.T. Xiao and C. Xie. "Research of Financial supportive Policy of the development of SMEs: A Literature Review," Social Science in Hunan, vol. 34, 2013, pp. 143-146.

[8] C. Lin, "Optimization research for policy implementer in multi-ethnic regions," Academic Forum, vol. 35, 2012, pp. 50-52.

[9] H. Ding and M.Y.Liang, "The design of evaluation index of public policy execution in local government: based on the perspective of legitimacy of local government," The Journal of Jiangsu Administration Institute, vol. 14, 2014, pp. 99-106.

[10] X.Y. Yin, "Exploration for influencing factors and countermeasures of Public Policy executive Power of local government," Journal of Qiqihar University (Philosophy \& Social Science Edition), vol. 45, 2016, pp. 4547.
[11] H.F. Song, "The analysis of government execution: based on the theory of human resource," Journal of Southwest University of Science and Technology (Philosophy and Social Science Edition), vol. 26, 2009, pp. 61-66.

[12] S.W. Zhan, and C. Lin. "Talk about the composition and promotion way of public policy execution," Journal of Commercial Economics, vol. 31, 2012, pp. 97-98

[13] R.L. Zhang and X.F. Wang. "resistance analysis for public policy execution of national fitness in our country," Journal of Shanghai University of Sport, vol. 37, 2013, pp. 1-5.

[14] S.H. Liu and S.P. Zhang, "The study of supervision countermeasures of local government for transformation and upgrade of SMEs," Seeker, vol. 32, 2012, pp. 31-33.

[15] J. Pan, "Canonical correlation analysis of Regional differences with infrastructure and government services for development of SMEs," Journal of Agrotechnical Economics, vol. 29, 2010, pp. 70-77.

[16] Q.K. Xie and Qing Tao. "The exploration of Government execution," Chinese Public Administration, vol. 23, 2007, pp. 9-13.

[17] A. H. Shi, "The analyses of problems and countermeasures for public policy execution of China local government," Journal of Heilongjiang Vocational Institute of Ecological Engineering, vol. 32, 2016, pp. 37-38.

[18] N. Guo, "The government? The market? Which is more effective: effectiveness research for mechanism of SMEs financing difficult," Journal of Financial Research, vol. 56, 2013, pp. 194-205.

[19] D.Q. Zhu and M.J. Zhang, "The legal regulation for folk financial activities," Journal of Zhengzhou University(Philosophy and Social Sciences Edition), vol. 55, 2014, pp. 54-58.

[20] L. Huang and J.Q. Zhang, "The research for the impact of strategy execution ability of Entrepreneurial to the strategy execution performance of enterprise: the evidence from small and medium-sized private entrepreneurs," Journal of Business Economics, vol. 29, 2009, pp. 28-33. 